\title{
Desenvolvimento profissional dos professores de Matemática: Uma experiência de formação em TIC
}

\author{
Patrícia Alexandra da Silva Ribeiro Sampaio \\ Universidade do Minho, Portugal
}

Resumo

A integração das TIC é uma prática que deverá ser tão natural ao professor como preparar aulas. No caso da Matemática, esta inclusão surge implícita nos programas oficiais, mas nem todos os docentes se sentem capazes. Neste texto apresenta-se uma experiência de formação sobre a utilização dos quadros interativos em contexto de sala de aula com 20 professores de Matemática, segundo o referencial TPACK da Matemática, que considera não só competências tecnológicas, como pedagógicas, de conteúdo, contextuais e todas as relações que se estabelecem. Pretendeu-se investigar se, e de que forma, a formação construída neste âmbito teria um impacto positivo na prática docente tendo-se, para o efeito, aplicado um questionário on-line aos professores, no fim da formação, após nove meses e passados três anos. Constatou-se uma mudança nas suas práticas letivas, mais próximas de um professor do século XXI, promovendo assim o desenvolvimento profissional dos professores de Matemática.

\section{Palavras-chave}

Desenvolvimento profissional; TPACK da Matemática; Tecnologia educativa; Quadros interactivos

\section{Introdução'}

A integração da tecnologia no processo de ensino/aprendizagem é uma tarefa que envolve vários fatores. Não se pode dissociar o conhecimento 
tecnológico do pedagógico e do conteúdo específico para uma efetiva incorporação das tecnologias educativas na sala de aula. Os professores de Matemática têm ao seu dispor um vasto conjunto de recursos que facilitam o cálculo, as representações geométricas e a representação gráfica de funções, devendo saber manusear e utilizar de forma criteriosa essas tecnologias educativas com os seus alunos. No entanto, nem todos os professores apresentam competências em Tecnologias de Informação e Comunicação (TIC) para o concretizarem. Deste modo, realizou-se uma formação de professores de Matemática, na modalidade de oficina, com o intuito de integrar a prática efetiva dos docentes na formação e permitir a partilha de diferentes experiências em contexto de sala de aula sobre a utilização dos quadros interativos (QI). Elaborou-se um questionário on-line para aferir a modificação das práticas letivas dos docentes face às TIC em momentos diferentes: no fim da formação, nove meses após a mesma e passados três anos. Trata-se de um estudo que seguiu o mesmo grupo num período em diferido para avaliar o efeito da formação no tempo.

Primeiramente, efetuou-se uma sucinta caraterização dos quadros interativos e das suas potencialidades como tecnologias educativas. De seguida, contextualizou-se o programa de formação em competências TIC, no âmbito do Plano Tecnológico da Educação (PTE) português, que visava a maioria dos docentes. Apresenta-se um referencial teórico, 'Technological Pedagogical Content Knowledge', ou seja, 'Conhecimento Tecnológico e Pedagógico do Conteúdo Matemático', denominado de TPACK da Matemática (Association of Mathematics Teacher Educators [AMTE], 2009; Niess et al., 2009), para se ensinar Matemática eficazmente com tecnologias, relatando-se e discutindo-se uma experiência de formação de acordo com este referencial teórico que permitiu o desenvolvimento profissional dos professores envolvidos.

\section{Quadro interativo - Uma tecnologia educativa}

Um quadro interativo é uma superfície que, quando ligada a um computador, permite controlar o dispositivo apontador que, normalmente, é controlado com o rato. Assim, cada toque no quadro, com um dedo ou uma caneta, dependendo do modelo, equivale a um clique do rato. Esta ferramenta educativa permite o controlo dos programas do computador; possibilita 0 registo do que é escrito/desenhado, podendo ser disponibilizado 
posteriormente aos alunos e/ou analisado pelo professor; permite a escrita livre, à mão, como um quadro branco; possibilita a escolha do fundo (uma grelha, um referencial cartesiano, uma figura...); apresenta uma ferramenta denominada caneta inteligente que facilita 0 desenho de diversas figuras geométricas; permite a realização de transformações como ampliações, reduções, rotações, em diversas formas, de uma maneira bastante fácil; dá a possibilidade de utilização de diversos applets disponíveis na Internet; etc. "No entanto, o quadro interativo tem o potencial para fazer muito mais - para ir além da apresentação de informação, fornecendo uma ferramenta para o ensino e aprendizagem interativo" (British Educational Communications and Technology Agency [BECTA], 2006, p. 3, trad. nossa).

Um quadro interativo facilita o trabalho do professor ao permitir a inserção de imagens, gráficos, folhas de cálculo, textos, acrescidos de anotações realizadas quer pelo docente quer pelos alunos; permite a adaptação de materiais em tempo real; possibilita um maior feedback. Não obstante, o quadro interativo apresenta algumas desvantagens: problemas tecnológicos não controláveis; elevado custo; é necessário ter cuidado com a posição de escrita para não causar sombra na projeção; a posição do quadro tem de ser pensada para não ser muito alta e de difícil acesso, nem baixa demais, dificultando a visualização.

Nos últimos anos têm-se realizado diversos estudos em Portugal sobre a integração dos quadros interativos no processo de ensino/aprendizagem, assim como sobre a relevância ou não da formação de professores neste âmbito. No caso específico da Matemática, Sampaio (2008) e Sampaio e Coutinho (2008) realizaram dois estudos em duas turmas do $7 .^{\circ}$ ano de escolaridade e concluíram que a motivação, a interação e a participação dos alunos nas atividades propostas nas aulas aumentaram. Ferreira (2009) conduziu um estudo em seis turmas do $5 .^{\circ}$ ano de escolaridade, em três escolas diferentes, na disciplina de Matemática, e concluiu que o uso do quadro interativo com a aplicação hipermédia desenvolvida nesse estudo promoveu maior empenho, interação e compreensão dos conteúdos lecionados.

Vicente e Melão (2009) levaram a cabo uma investigação sobre a adoção do quadro interativo por professores de Matemática em cinco escolas, com a participação de 23 professores do $3 .^{\circ}$ ciclo do ensino básico, e concluíram que a introdução desta tecnologia nas suas aulas foi realizada na 
grande generalidade sem qualquer planeamento. Este recurso ainda não era usado pela maioria dos docentes ou era utilizado de uma forma menos interativa, não fazendo uso das suas potencialidades, tendo os professores salientado a escassez de tempo para prepararem atividades com esta tecnologia, a falta de formação específica, a enorme dificuldade em solucionar questões técnicas e o baixo número de quadros interativos disponíveis. Ferreira e Meirinhos (2011) realizaram um estudo com 71 professores e concluíram que cerca de metade não tinha feito formação sobre a utilização pedagógica do quadro interativo, apenas cerca de um terço utilizava esta ferramenta com frequência e poucos professores produziam as suas próprias atividades para utilizar com o quadro interativo, tendo os professores salientado também a escassez de tempo para prepararem atividades com esta tecnologia e dificuldades em solucionar questões técnicas.

Mouraz e Sousa (2011) analisaram os resultados do projeto Inovar com QI, que se desenvolveu ao longo de três anos, e apuraram que o uso do quadro interativo nas aulas era uma constante, mas apenas metade usava ferramentas próprias do quadro interativo e cerca de um terço dos professores preparava as suas atividades específicas para usar com o quadro interativo. A "integração [do quadro interativo] existiu e foi sendo progressivamente mais diversificada, tanto quanto a sensação de familiaridade dos professores com a tecnologia e a progressiva exigência dos conteúdos a leccionar foi estimulando" (Mouraz \& Sousa, 2011, p. 84). Guimarães e Carvalho (2011) analisaram a reação de três grupos de professores de Matemática e Ciências da Natureza que frequentaram formação em quadros interativos no âmbito do Plano Tecnológico da Educação (PTE) e concluíram que a formação teria sido mais vantajosa se fosse na modalidade de oficina, tendo realçado a importância de acompanhar ao longo do tempo os professores que receberam formação para verificar o seu impacto nas práticas letivas. Num estudo mais amplo, Guimarães e Carvalho (2012) já analisaram a reação de dezanove grupos de professores que frequentaram essa formação e concluíram que passado um ano poucos professores adotavam o quadro interativo como ferramenta pedagógica, não conseguindo coordenar o conhecimento do conteúdo com o pedagógico e o tecnológico.

Sampaio e Coutinho (2013) sintetizam: "Mas, afinal, para quê utilizar um QI? O objetivo principal é criar um ambiente de aprendizagem em que os alunos estejam empenhados ativamente no processo de ensino- 
aprendizagem" (p. 744). Apesar de já existirem alguns estudos sobre como o quadro interativo é usado pelos professores, torna-se relevante verificar como a formação específica poderá contribuir para a prática letiva dos professores neste âmbito e, em particular, se ocorrem alterações ao longo do tempo.

\section{Formação em competências TIC - PTE}

A sociedade em que vivemos já não permite uma discriminação negativa das tecnologias nas salas de aulas, de tal forma que "as escolas e as salas de aula, tanto presenciais quanto virtuais, devem ter professores equipados com recursos e habilidades em tecnologia que permitam realmente transmitir o conhecimento ao mesmo tempo que se incorporam conceitos e competências em TIC" (UNESCO, 2009, p. 1). Neste âmbito, a UNESCO (2009) criou um conjunto de Padrões de Competência em TIC para Professores (ICT-CST, em Inglês) com base em três abordagens: alfabetização em tecnologia, aprofundamento do conhecimento e criação de conhecimentos, e segundo seis componentes do sistema educacional: política, currículo, pedagogia, TIC, organização e desenvolvimento profissional de docentes.

De forma semelhante, o governo português, preocupado com a integração das TIC nas escolas, através da Resolução do Conselho de Ministros n. ${ }^{\circ}$ 137/2007, criou o PTE, que visa contribuir para uma escola de futuro e que se estrutura em três eixos temáticos de intervenção: tecnologia, conteúdos e formação. Em 2009, através da Portaria n. ${ }^{\circ}$ 731/2009, foram estabelecidas as condições normativas para a execução do programa de formação e de certificação de competências TIC, criando-se o sistema de formação e de certificação em competências TIC para docentes, organizado em três níveis: competências digitais (nível 1), competências pedagógicas e profissionais com TIC (nível 2), competências avançadas em TIC na educação (nível 3).

A certificação de competências básicas que possibilitam "uma utilização instrumental das TIC como ferramentas funcionais no seu contexto profissional" (Ministério da Educação [ME], 2009, p. 4341) reporta-se às competências digitais. Por exemplo, um docente deve saber organizar as pautas de avaliação dos seus alunos em folhas de cálculo. Já a certificação de competências "que o habilitam a integrar as TIC nas suas práticas, 
explorando-as como recurso pedagógico e didáctico e mobilizando-as para o desenvolvimento de estratégias de ensino, numa perspectiva de melhoria da qualidade do processo de aprendizagem dos alunos" (ME, 2009, p. 4342) reporta-se às competências pedagógicas e profissionais com TIC. Por exemplo, um docente deve saber como integrar um quadro interativo na planificação das suas aulas. Por fim, a certificação de competências "que o habilitam a inovar práticas pedagógicas com as TIC, a gerir as suas experiências e reflexões numa perspectiva investigativa e num sentido de partilha e colaboração com a comunidade educativa" (ME, 2009, p. 4342) reporta-se às competências avançadas em TIC na educação.

Através do PTE procedeu-se à modernização tecnológica das escolas, sendo a formação um dos três eixos de intervenção. Assim, nas escolas encontra-se disponível um conjunto muito variado e vasto de recursos materiais de forma a se implementarem metodologias de ensino apoiadas nas TIC, tentando promover-se a qualidade de ensino e a melhoria das aprendizagens dos alunos. O Programa de Formação de Competências TIC do PTE pretendeu envolver $90 \%$ dos docentes, ao longo de quatro anos (2010-2013), e em 2010 foi concluída a instalação de 5613 quadros interativos com videoprojetor nas salas de aula com o objetivo de permitir práticas pedagógicas mais inovadoras e interativas.

No entanto, nem sempre o investimento financeiro efetuado, mesmo que de enorme dimensão, motiva uma resposta apropriada por parte dos professores e das escolas (Costa, 2012; Mueller, Wood, Willoughby, Ross, \& Specht, 2008). Para ocorrer uma efetiva integração das TIC na sala de aula, o professor deve transformar as experiências de aprendizagem de forma a produzir um impacto significativo nos níveis mais altos de realização para os alunos (Puentedura, 2013).

\section{TPACK da Matemática}

A integração da tecnologia no processo de ensino/aprendizagem tem sido um tema de investigação contínuo, debruçando-se várias vezes sobre as vantagens e desvantagens da tecnologia (Sampaio \& Coutinho, 2013; Sandholtz, Ringstaff, \& Dwyer, 1997). É agora consensual a importância de focar não na tecnologia em si, mas, ao invés, no modo como é utilizada (Koehler \& Mishra, 2005). Afinal o que os professores necessitam de saber sobre a tecnologia e como podem adquirir esse conhecimento? Segundo 
Mishra e Koehler (2006),

"as relações entre o conteúdo (o assunto atual que deve ser aprendido e ensinado), pedagogia (o processo e a prática ou métodos de ensino e aprendizagem) e tecnologia (ambos comuns, como quadros negros, e avançadas, tais como computadores digitais) são complexas" (p. 1025).

A qualidade do ensino requer o desenvolvimento de uma compreensão diferenciada das complexas relações entre tecnologia, conteúdo e pedagogia, e usar essa compreensão para desenvolver estratégias específicas do contexto e representações.

O professor deve dominar a pedagogia $(\mathrm{P})$ - as estratégias e teorias de aprendizagem - e o conteúdo (C) que leciona; e se apresentar bons conhecimentos de conteúdo e boa aplicação das teorias de aprendizagem, mas sem recurso à tecnologia, será um professor competente do século $\mathrm{XX}$, isto é, bom, mas desatualizado. O professor deve ainda dominar a tecnologia (T), estar apto a dar suporte tecnológico aos alunos e aos outros recursos humanos. Se usar os conhecimentos tecnológicos e pedagógicos na sala de aula, mas as atividades estiverem desligadas das aprendizagens essenciais, será um professor excitante, mas desconectado. Se usar a tecnologia para realçar a exploração do conteúdo, mas sem a pedagogia adequada, será um professor moderno, mas limitado. Por fim, um professor do século XXI usa práticas pedagógicas bem contextualizadas nos currículos e nas teorias de aprendizagem suportadas pela tecnologia (TPACK).

Puentedura (2013) desenvolveu o modelo 'Substitution, Augmentation, Modification, Redefinition' (SAMR), que evidencia a transição entre os diferentes níveis de integração da tecnologia na sala de aula. Os dois primeiros componentes deste modelo (Substituição e Aumento) procuram a melhoria das atividades de aprendizagem com o uso das TIC, os outros dois componentes (Modificação e Redefinição) já têm o propósito de transformar, com o uso das TIC, as atividades de aprendizagem propostas pelos docentes. Pode-se estabelecer um paralelo entre o modelo SAMR e o referencial TPACK (figura 1). No caso particular da tecnologia quadro interativo, no nível da Substituição, o quadro interativo é usado apenas como um mero recurso, em substituição de outro e sem trazer qualquer melhoria funcional à sala de aula. Por exemplo, como uma tela branca. Não se enquadra no referencial TPACK. No nível do Aumento, já ocorre uma melhoria funcional da tecnologia, mas ainda sem transformação. Por exemplo, já se realizam anotações no 
quadro interativo e manipulam-se recursos, acrescentam-se páginas e guardam-se as aulas... São necessários diferentes conhecimentos, mas ainda não apresenta nenhum conhecimento proveniente das várias interseções do referencial TPACK. No nível da Modificação, o quadro interativo já permite redesenhar as atividades de aprendizagem para ocorrer transformação na aprendizagem dos alunos. Por exemplo, usa-se a galeria de imagens e as ferramentas interativas que vêm com o software do quadro interativo. Vários dos recursos escondidos na galeria podem transformar as aulas. A forma de assimilação do conteúdo por parte dos alunos muda. Assim, as interseções de conhecimento do referencial TPACK são necessárias para o professor redesenhar as atividades. Por fim, no nível da Redefinição as tarefas propostas aos alunos com o uso do quadro interativo já permitem a transformação da capacidade de pensamento de ordem superior. Por exemplo, são criadas questões para os alunos responderem no decorrer da aula em que o professor e/ou a turma sabe $(\mathrm{m})$ de imediato quem respondeu corretamente. Há uma efetiva transformação de atitude na sala de aula. Deste modo, a interseção de todos os tipos de conhecimento manifesta-se, estamos perante o TPACK.

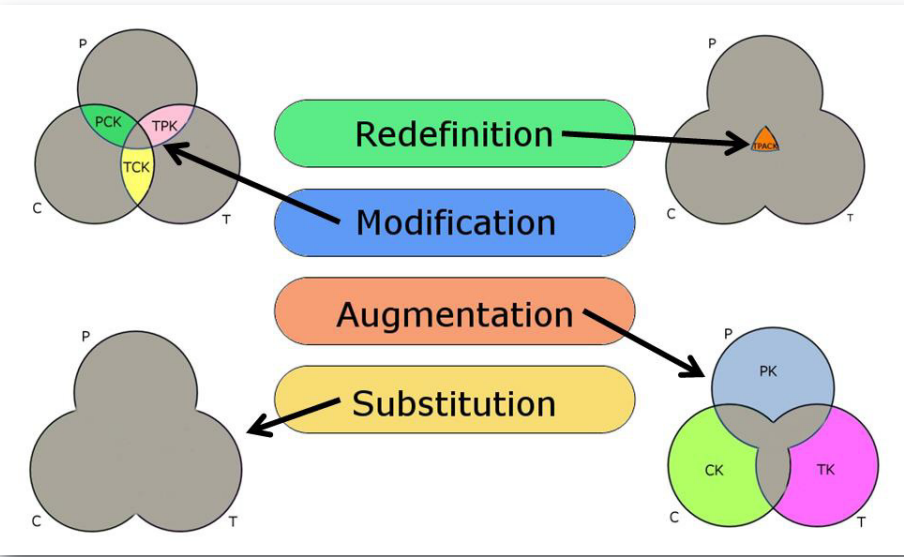

Figura 1 - SAMR e TPACK (adaptado de Puentedura, 2013)

E no caso específico da Matemática: afinal, o que significa usar a tecnologia no contexto do processo de ensino/aprendizagem? "O que será 
que o professor precisa [de] saber para ensinar de forma eficiente em contextos tecnológicos? Que ferramentas teóricas têm sido construídas para estudar essa questão?" (Palis, 2010, pp. 432-433). Segundo Niess (2006), o TPACK é um referencial teórico importante para o ensino da Matemática que deve ser desenvolvido no processo de ensino/aprendizagem. Para se ensinar Matemática, torna-se necessária uma compreensão profunda da Matemática (conteúdo), do processo de ensino/aprendizagem (pedagogia) e da tecnologia. E, mais relevante do que estes domínios de conhecimento isoladamente, os professores necessitam de um conhecimento integrado destes diferentes domínios.

Para Niess (2006), a formação contínua de docentes deve ajudá-los a tornarem-se bem informados sobre a tecnologia, sendo desafiados a integrála no ensino, "necessitando de reconhecer e emanar das experiências dos professores e proporcionar-lhes experiências estendidas no ensino da Matemática com a tecnologia" (p. 198). Os professores necessitam de construir uma atitude reflexiva e profissional sobre as ferramentas usadas no ensino da Matemática.

Como sabemos a evolução da tecnologia é constante, apesar de a sua efetiva integração em contexto de sala de aula parecer que anda sempre um passo atrás. Desde 2007 que o Comitê de Tecnologia da AMTE (Association of Mathematics Teacher Educators) está a tentar desenvolver um quadro teórico de integração do TPACK no processo de ensino/aprendizagem da Matemática, tendo sido proposto, em 2009, o referencial "Mathematics TPACK", organizado em torno de quatro áreas:

1. Conceção e desenvolvimento de experiências e ambientes de aprendizagem matemáticos com apoio tecnológico;

2. Orientação da educação matemática com ferramentas tecnológicas integradas;

3. Avaliação de ambientes de ensino/aprendizagem matemáticos apoiados por tecnologias;

4. Envolvimento no desenvolvimento profissional contínuo para melhorar o conhecimento do conteúdo tecnológico pedagógico. (AMTE, 2009)

Niess et al. (2009) apresentaram este referencial teórico organizado de forma semelhante ao proposto pelo Comitê de Tecnologia da AMTE (2009), 
tendo avançado com um modelo que descreve a progressão em níveis pelo TPACK da Matemática à medida que os professores integram a tecnologia no processo de ensino/aprendizagem da Matemática, inspirado no modelo de processo de decisão de inovação introduzido por Rogers (2003). De acordo com esse modelo, os professores precisam de passar por um processo de cinco etapas para enfrentarem a decisão final de aceitar ou rejeitar uma inovação específica para o ensino da Matemática com tecnologia, neste caso com o QI: 1. ${ }^{a}$ reconhecer (conhecimento), 2. ${ }^{a}$ aceitar (persuasão), 3. ${ }^{a}$ adaptar (decisão), 4. ${ }^{a}$ explorar (implementar), 5. ${ }^{a}$ avançar (confirmação). Este processo de desenvolvimento do TPACK não é linear, já que a transição de um nível para o outro não apresenta uma progressão regular. Um professor pode situar-se em diferentes níveis relativamente a diferentes aspetos da sua atividade docente e, de igual modo, algumas experiências podem conduzir a uma regressão do nível ou podem permitir uma predisposição para a aceitação de outra tecnologia.

\section{Método}

A presente investigação tem como objetivo geral analisar o desenvolvimento profissional dos professores de Matemática relativamente à efetiva integração das TIC no processo de ensino/aprendizagem, em particular de quadros interativos, após a frequência de uma formação sobre a utilização de quadros interativos em contexto de sala de aula. Deste objetivo surge então a seguinte questão de investigação: após a formação que os professores de Matemática frequentaram ocorreu modificação das suas práticas letivas face às TIC?

Realizou-se uma formação, na modalidade de oficina, para integrar efetivamente a experimentação em contexto de sala de aula, em que participaram 20 professores de Matemática dos $2 .^{\circ}$ e $3 .^{\circ}$ ciclos do Ensino Básico, recrutados voluntariamente, todos a lecionar na mesma instituição, situada no norte de Portugal. O formador também é professor de Matemática e é reconhecido pelo Conselho Científico-Pedagógico da Formação Contínua nas áreas das TIC e da Didática da Matemática. A formação surgiu como uma resposta às solicitações desse grupo de professores. A metodologia adotada em toda a formação seguiu as linhas do referencial teórico TPACK da Matemática, que implica vários tipos de conhecimento e não apenas o tecnológico. A turma era composta quer por docentes contratados quer por 
docentes dos quadros da escola, apresentando experiências de ensino muito variadas: metade trabalhava com alunos há menos de 10 anos, 35\% praticava a docência há entre 10 e 20 anos, e 15\% já possuía uma experiência de ensino superior a 20 anos.

Optou-se por uma oficina, dentro das várias modalidades de formação contínua de professores, pelo caráter obrigatório de trabalho autónomo dos docentes. Trata-se de um tipo de formação contínua dominantemente realizada segundo componentes do saber-fazer prático. Neste caso, os docentes produziram materiais de intervenção concretos, asseguraram a utilidade desses produtos pela prática efetiva em contexto de sala de aula, refletiram sobre as práticas desenvolvidas e reforçaram a partilha de experiências.

Para aferir uma possível mudança de atitude dos professores nas suas práticas letivas no que se refere à integração das TIC e, em particular, do quadro interativo, no processo de ensino/aprendizagem, estes professores responderam a um questionário, on-line, anonimamente, no fim da formação, nove meses após, e três anos mais tarde, tendo-se mantido sempre a possibilidade de contacto entre formador e formandos. Optou-se por estes três momentos específicos para tentar avaliar a opinião dos professores logo após a formação, passado um ano escolar (nove meses) e decorrido mais algum tempo (três anos) para estes docentes já terem tido oportunidade para experimentar novas metodologias e formarem uma opinião sobre a sua aceitação ou não (Guimarães \& Carvalho, 2012; Niess, 2015): "[o] envolvimento dos professores com novas ideias para ensinar com tecnologias digitais requer tempo para uma efetiva transformação da sua maneira de pensar sobre como ensinar o conteúdo com a tecnologia" (Niess, 2015, p. 23).

Esta formação foi elaborada tendo em conta a proposta do modelo TPACK de professores do século XXI. Apenas professores de Matemática a frequentaram. Não se tratou de uma formação generalista sem enfoque no conteúdo específico da disciplina, neste caso da Matemática. Abordaram-se conceitos tecnológicos específicos dos quadros interativos, tendo-se trabalhado em específico os softwares 'Interwrite Workspace' e 'Activinspire', por serem os existentes na escola, considerando-se assim o contexto, tal como sugerem Koehler e Mishra (2008). No entanto, não se tratou de uma formação focada na tecnologia em si. Salientaram-se e discutiram-se com os formandos vantagens do uso dos quadros interativos em contexto educativo, 
mas também possíveis constrangimentos. Foram explorados exemplos de aulas de Matemática com recurso ao quadro interativo que foram bem sucedidos, interligando o conhecimento tecnológico com o pedagógico e o de conteúdo num contexto específico. A obrigatoriedade de produção de tarefas matemáticas com recurso ao quadro interativo, para atingir objetivos específicos, e sua aplicação com alunos, visava um nível superior de integração do quadro interativo na sala de aula do modelo SAMR: transformação. Por fim, a partilha e reflexão destas experiências num momento final da formação pretendia uma análise crítica sobre a integração da tecnologia na sala de aula.

Nesta investigação utilizou-se o inquérito por questionário na tentativa de obter informação sobre: 1- se os professores utilizam as TIC na sala de aula; 2- se usam os quadros interativos nas suas aulas; 3 - qual a autoperceção do nível de competência na utilização das TIC na prática docente; 4- quais as vantagens e desvantagens do uso dos quadros interativos em contexto educativo; 5- que dificuldades sentiram com o uso do quadros interativos na sala de aula; 6- o grau de utilidade da formação na prática docente; 7- a possível contribuição da formação para a melhoria das aprendizagens dos alunos. O questionário era constituído por seis questões de carácter pessoal relativas à identificação do inquirido, cinco questões fechadas e três questões abertas, de resposta curta.

Após a elaboração da primeira versão do questionário, este foi revisto por dois especialistas e aplicado a quatro professores de Matemática, semelhantes aos da amostra, de modo a aferir a qualidade informativa das respostas obtidas no sentido de percebermos se poderíamos obter a informação de que precisávamos. Todos os formandos foram contactados por e-mail para responderem aos questionários anonimamente através do Google Drive e a taxa de resposta foi sempre de $100 \%$. O uso do questionário on-line foi propositado, pois era o melhor meio para se obter o pleno de respostas tendo em conta que se pretendia acompanhar os professores muito depois da formação recebida.

\section{Resultados e discussão}

Pelo apetrechamento das escolas com quadros interativos, através do PTE, os professores de Matemática sentiram a necessidade de realizar formação sobre a integração desta tecnologia educativa nas suas aulas. 
Deste modo, vinte professores de Matemática participaram numa oficina de formação, com a duração de 50 horas, decorrida ao longo de várias sessões, durante três meses.

Constatou-se que ocorreu uma evolução na integração das TIC na prática docente, sendo que no fim da formação 35\% dos professores consideravam que não utilizavam as TIC de forma eficiente nas suas aulas, diminuindo para $25 \%$ quer passados nove meses quer decorridos três anos. O desenvolvimento profissional dos professores envolve um processo contínuo de melhoria de práticas com o intuito de se promoverem mudanças educativas que visem a melhoria da qualidade de ensino e "concretiza-se com uma atitude permanente de pesquisa, de questionamento e de busca de soluções" (Garcia, 1999, p. 137). Além disso, deve ser visto como um processo e não como um simples evento (Loucks-Horsley, Hewson, Love, \& Stiles, 1998).

Relativamente à perceção de autoeficácia dos professores sobre o grau de competência na utilização das TIC na prática da sala de aula, ocorreu um incremento relevante, já que logo após a formação pouco mais de metade (55\%) atribuía um grau de competência bom ou muito bom à utilização das TIC na sua prática letiva e após três anos esse valor aumentou para $85 \%$ (Gráfico 1). Deste modo, ocorreu transição entre os diferentes níveis de integração da tecnologia na sala de aula do modelo SAMR.

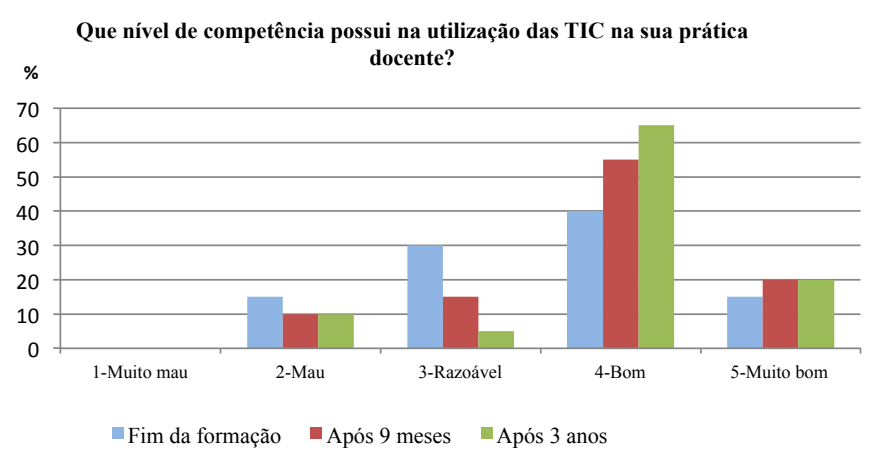

Gráfico 1 - Autoperceção do nível de competência na utilização das TIC na prática docente, no fim da formação, nove meses após e três anos depois 
Relativamente ao uso específico do quadro interativo nas aulas de Matemática, constata-se uma diminuição dos professores que diz que não o costuma fazer e um aumento dos que dizem que o usam com maior frequência (Gráfico 2). A integração de uma tecnologia na prática letiva de um professor é um processo lento e precisa de uma certa maturação para gerar transformação (Guskey, 2002), é um processo complexo e a experiência profissional pode conduzir a uma regressão ou a uma predisposição para 0 uso (Niess et al., 2009).

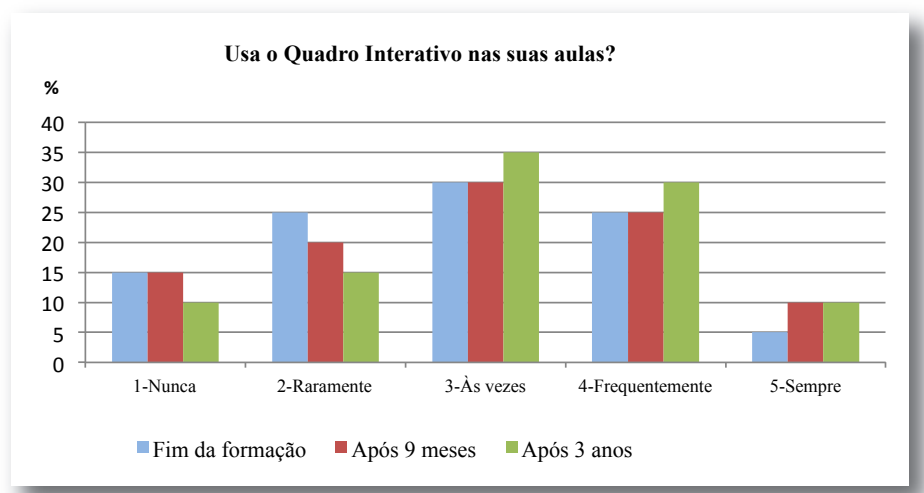

\section{Gráfico 2 - Utilização do quadro interativo por parte dos professores, no fim da formação, nove meses após e três anos depois}

Apesar de vários estudos terem salientado diversas vantagens do uso do quadro interativo em contexto de sala de aula, é necessário realçar que há uma variação considerável neste uso tanto dentro dos departamentos das escolas como entre temas centrais da mesma disciplina; a sua introdução não permite, em si, transformar pedagogias existentes; deve ocorrer uma maior discussão entre os colegas sobre como pode ser usado o quadro interativo para apoiar, ampliar e transformar a prática existente; em geral, o modo como os docentes desfrutam das potencialidades do quadro interativo está relacionado com o objetivo pedagógico e não com o tecnológico; e a observação da tecnologia em uso mostra uma variação considerável na abordagem que os professores fazem da mesma e, consequentemente, os prováveis benefícios para os alunos (Moss et al., 2007). 
Apesar de a formação ser sobre uma tecnologia específica (quadros interativos), não se podendo generalizar como TIC, o seu contributo para a melhoria do grau de competência na utilização das TIC na prática da sala de aula dos docentes também não pode ser menosprezado. Três anos após a formação, os docentes afirmaram que utilizam as TIC com mais frequência, não só os quadros interativos, mas na generalidade. Esta oficina de formação ajudou-os a criar aulas mais interativas promovendo lições mais ativas e dinâmicas que permitem facilitar a aprendizagem dos alunos de variados conceitos matemáticos. As várias interseções de conhecimento do referencial TPACK são necessárias para o professor conseguir construir essas tarefas matemáticas. Segundo Guskey (2002), as experiências positivas podem modificar as atitudes dos professores, provocando alterações efetivas na prática pedagógica. Como os professores experimentaram e viram funcionar, registando um impacto positivo, ficaram mais abertos à utilização das TIC na sala de aula. Miller, Glover, e Averis (2004) apresentam um conjunto de conselhos para professores de Matemática relativamente à integração do quadro interativo nas suas salas de aula, salientando que as aulas devem ter objetivos claros, ser planeadas como uma sequência, permitir diferentes estilos de aprendizagem, incorporar diferentes abordagens para reforçar a compreensão conceitual, incluir diversas atividades interativas, integrar uma avaliação formal e informal, permitir a revisão de conceitos e ser divididas em segmentos com introdução, desenvolvimento e conclusão.

De acordo com Niess (2005), a formação contínua de professores no âmbito das TIC costuma centrar-se apenas em conhecimentos tecnológicos, esquecendo-se das questões pedagógicas, mas esta formação foi elaborada de acordo com o quadro TPACK da Matemática, respeitando a especificidade da disciplina, apresentando preocupações quer pedagógicas quer tecnológicas, e considerando o contexto de cada professor e respetivos alunos. A opção de oficina de formação, dentro das várias modalidades de formação, foi intencional tendo em conta o caráter de trabalho autónomo dos docentes, com aplicação em contexto de sala de aula, reforçando-se a experiência de todos. Segundo Nóvoa (1992) um professor não pode dissociar o eu-pessoal do eu-profissional, sendo importante aproximá-los. A capacidade de pensar de forma reflexiva sobre o seu desempenho e a cooperação entre professores são o caminho para o desenvolvimento profissional (Schön, 1992). A formação contínua é uma das formas de 
promover a reflexão dos professores e promover mudanças na prática docente. Para Tardif (2002), a relevância e o proveito da participação dos docentes em formações estão diretamente relacionados com a valorização das suas experiências, estabelecendo-se assim uma relação efetiva entre as suas práticas e outros saberes.

Uma das vantagens referidas pelos professores da utilização dos quadros interativos nas suas aulas é a motivação dos alunos, tal como verificado por Sampaio (2008) e Sampaio e Coutinho (2008) e referido na literatura por Miller, Glover, e Averis (2005). Outra vantagem é a possibilidade de reutilização de materiais, que foi também constatada por Glover e Miller (2002) e Walker (2002). De forma semelhante ao reportado na literatura por Ball (2003) e Miller (2003), os docentes referiram a possibilidade de maximizar o tempo útil da aula pela estrutura da própria aula, com materiais previamente construídos para o efeito. A possibilidade de criação de materiais interativos foi um dos aspetos salientados pelos docentes como bastante atrativo, tal como constatado também por Ball (2003) e BECTA (2006). O acesso a novas ferramentas pela possibilidade de integração das mesmas na prática letiva foi verificado por Sampaio (2008) e referido na literatura por Levy (2002). Por fim, os docentes mencionaram ainda a importância da troca de ideias com os colegas, permitindo a partilha de experiências e promovendo a aquisição de práticas de cooperação. Os professores também referiram algumas desvantagens, como o elevado custo do equipamento, que implica que nem todas as salas estejam equipadas com quadros interativos, tal como constatado por Sampaio e Coutinho (2011). Referiram, ainda, o tempo que é necessário para a construção de materiais e que consideram demasiado, ideia coincidente com as conclusões da investigação nacional realizada por Ferreira e Meirinhos (2011) e, em contexto internacional, por Hall, Chamblee, e Hughes (2008).

Relativamente à maior dificuldade sentida pelos docentes no uso do quadro interativo nas suas aulas, na generalidade, os professores referiram que inicialmente apenas viam o quadro interativo como uma tela branca para usar com o Power Point, mas, em vez de estarem sentados em frente ao computador, usavam a caneta diretamente na tela. Neste caso, os docentes apresentavam características de nível inferior do modelo SAMR. Com a formação, perceberam que a potencialidade do quadro interativo era muito maior. A partilha de exemplos concretos de utilização do quadro interativo em 
contexto de sala de aula - que envolvia representações visuais mais claras de certos conceitos, atividades que incentivam a uma abordagem mais ativa dos alunos, uma possível ilustração dos conceitos de diferentes maneiras, etc. e a discussão crítica dessas aulas com os colegas, para conhecerem o feedback dos alunos e das aprendizagens, foi determinante para perspetivarem as tarefas matemáticas com recurso ao quadro interativo de outra forma, tal como constatado por Mouraz e Sousa (2011). Passados nove meses da formação, os docentes referiram que nem sempre conseguiam utilizar esta ferramenta educativa porque simplesmente não está disponível em várias salas de aula e que a construção de materiais específicos, por vezes, torna-se demorada, necessitando ainda de um reforço sobre o conhecimento tecnológico do quadro interativo. Passados três anos da formação, a maior dificuldade sentida pelos docentes relativamente ao uso do quadro interativo é a falta de assistência técnica nas escolas: por exemplo, há canetas que já não estão a estabelecer uma boa conexão com o quadro, precisando de substituir a ponteira; as lâmpadas dos projetores também precisam de ser substituídas; o software dos quadros e dos computadores necessita de atualizações; entre outros.

Estes docentes foram ainda questionados sobre o grau de utilidade desta oficina de formação na sua prática letiva, tendo-se obtido exatamente os mesmos resultados em qualquer um dos momentos de aplicação dos questionários, isto é, uma média de 4,1 numa escala de 1 (nada útil) a 5 (muito útil). Já relativamente a uma possível contribuição da formação para melhorar a aprendizagem dos alunos, obteve-se uma média de 3,75, numa escala de 1 (nada) a 5 (completamente), quer passados nove meses quer passados três anos, ocorrendo um pequeno aumento $(0,25)$ relativamente à opinião dos professores no fim da formação.

\section{Considerações finais}

Nos últimos 25 anos têm surgido diversos projetos que permitiram o equipamento das escolas portuguesas com tecnologia diversa. No entanto, a maioria desses projetos baseava-se apenas no fornecimento de computadores, internet de banda larga, projetores multimédia, etc., ignorando quase por completo o desenvolvimento profissional dos professores. O último projeto de grande escala do governo português, o Plano Tecnológico da Educação, já se baseava em três eixos de intervenção, contemplando 
também a formação docente. $O$ desenvolvimento profissional docente é um processo "que se deve contextualizar no local de trabalho do docente - a escola - e que contribui para o desenvolvimento das suas competências profissionais através de experiências de diferente índole, tanto formais como informais" (Marcelo, 2009, p. 10).

Realizou-se uma oficina de formação sobre a incorporação dos quadros interativos no processo de ensino/aprendizagem da Matemática como forma de os docentes transformarem a sua prática letiva. Através das suas experiências e partilha das mesmas procurou-se a integração da tecnologia com a pedagogia e o conteúdo curricular, segundo o TPACK da Matemática. A tecnologia em si não apresenta um valor acrescentado, fazendo variar fortemente o seu impacto de acordo com a forma como é utilizada pelo docente em contexto de sala de aula.

A tecnologia é imposta aos professores, não há como escapar dela, mas como a usar de forma eficiente em Matemática? Mishra e Koehler (2006) acreditam que o ensino é uma atividade altamente complexa que utiliza vários tipos de conhecimento: pedagógico, tecnológico e do conteúdo. É necessário um conhecimento flexível para atender às complexas interações que ocorrem entre conteúdo, pedagogia, tecnologia e contexto. Desde o reconhecimento de que a tecnologia pode ou não ser útil em Matemática até à integração efetiva em contexto de sala de aula e sua avaliação, há um longo caminho a percorrer. Através desta experiência e sua avaliação, ao longo de três anos, observou-se uma evolução positiva de aceitação das TIC em contexto de sala de aula por parte dos professores e um aumento na perceção de autoeficácia do grau de competência na utilização das tecnologias educacionais, verificando-se que formações acompanhadas que valorizam vários aspetos para além do manuseamento da tecnologia são úteis para a prática docente e desenvolvimento profissional.

Salienta-se que desenhar uma formação para professores não se resume a selecionar um conjunto de conteúdos, objetivos, recursos e recrutar um formador. Deve ser um processo que surja da vontade/necessidade dos professores, fazendo parte de um todo coerente. A escolha da modalidade de formação é essencial. A dinâmica das sessões presenciais não deve ser exclusivamente teórica ou sem recurso à experimentação e deve ser capaz de mobilizar os professores para a experimentação e reflexão. 
Convém referir que os resultados da investigação foram construídos com base no que os professores participantes disseram que faziam e/ou pensavam, o que constitui uma limitação. Através deste estudo verificamos que, pela frequência de uma formação construída segundo o modelo TPACK Matemático, ocorreu transição entre os diferentes níveis de integração do quadro interativo na sala de aula do modelo SAMR (Substituição, Aumento, Modificação, Redefinição) e seria pertinente que, em futuras investigações, se analisasse em pormenor como ocorreram essas transições.

\section{Notas}

1 Artigo redigido no âmbito de uma bolsa de doutoramento SFRH/BD/71323/2010 financiada pela Fundação para a Ciência e Tecnologia (FCT).

\section{Referências}

Association of Mathematics Teacher Educators - AMTE (2009). Mathematics TPACK (Technological Pedagogical Content Knowledge) framework. Disponível em: http://amte.net/sites/all/themes/amte/resources/MathTPACKFramework.pdf

Ball, B. (2003). Teaching and learning mathematics with an interactive whiteboard. Micromath, 19(1), 4-7.

British Educational Communications and Technology Agency - BECTA (2006). Teaching interactively with electronic whiteboards in the primary phase. Disponivel em: http://www.becta.org.uk/ (consultado a 25/08/2008)

Costa, F. (2012). Desenvolvimento curricular e TIC: Do déficit tecnológico ao déficit metodológico. In A. Estrela \& J. Ferreira (Eds.), Revisitar os estudos curriculares - Onde estamos e para onde vamos? (pp. 159-171). Lisboa: Secção Portuguesa da AFIRSE.

Ferreira, A., \& Meirinhos, M. (2011). Utilização de quadros interactivos multimédia numa escola do ensino básico. In V. Gonçalves, M. Meirinhos, A. Valcarcel, \& F. Tejedor (Eds.), Conferência Ibérica: Inovação na educação com TIC (pp. 337351). Bragança: Instituto Politécnico de Bragança, Escola Superior de Educação.

Ferreira, P. (2009). Quadros interactivos: Novas ferramentas, novas pedagogias, novas aprendizagens (Dissertação de Mestrado). Universidade do Minho, Braga.

Garcia, C. (1999). Formação de professores - Para uma mudança educativa. Porto: Porto Editora.

Glover, D., \& Miller, D. (2002). The interactive whiteboard as a force for pedagogic change: The experience of five elementary schools in an English education authority. Information Technology in Childhood Education, 1, 5-19. 
Guimarães, D., \& Carvalho, A. (2011). A formação de professores em quadros interactivos multimédia: Reacção de três grupos de formandos. In A. Lozano, M. Uzquiano, A. Rioboo, J. Blanco, B. Silva, \& L. Almeida (Orgs.), XI Congreso Internacional Galego-Portugués de Psicopedagoxia (pp. 701-711). Coruña: Universidade de Coruña.

Guimarães, D., \& Carvalho, A. (2012). Formação de professores em quadros interativos multimédia: Um estudo de caso no Centro de Formação de Associação de Escolas de Sousa Nascente. In J. Matos et al. (Orgs.), II Congresso Internacional TIC e Educação - ticEDUCA 2012 (pp. 2280-2295). Lisboa: Instituto de Educação da Universidade de Lisboa.

Guskey, T. (2002). Professional development and teacher change. Teachers and Teaching: Theory and Practice, 8(3/4), 381-391.

Hall, J., Chamblee, G., \& Hughes, T. (2008). Teacher perceptions of interactive whiteboards: A comparison of users and future-users in high school and middle school mathematics. In K. McFerrin et al. (Eds.), Proceedings of Society for Information Technology \& Teacher Education International Conference 2008 (pp. 4461-4467). Chesapeake, VA: AACE.

Koehler, M., \& Mishra, P. (2005). What happens when teachers design educational technology? The development of Technological Pedagogical Content Knowledge. Journal of Educational Computing Research, 32(2), 131-152.

Koehler, M., \& Mishra, P. (2008). Introducing TPCK. In AACTE Committee on Innovation and Technology (Eds.), Handbook of Technological Pedagogical Content Knowledge (TPCK) for educators (pp. 3-29). New York: Routledge.

Levy, P. (2002). Interactive whiteboards in learning and teaching in two Sheffield schools: A developmental study. Department of Information Studies, University of Sheffield.

Loucks-Horsley, S., Hewson, P., Love, N., \& Stiles, K. (1998). Designing professional development for teachers of science and mathematics. Thousand Oaks, CA: Corwin Press.

Marcelo, C. (2009). Desenvolvimento profissional docente: Passado e futuro. Sísifo Revista de Ciências da Educação, 8, 7-22.

Miller, D. (2003). Developing interactive whiteboard activity. MicroMath, 19, 33-35.

Miller, D., Glover, D., \& Averis, D. (2004). Enhancing mathematics teaching through new technology: The use of the interactive whiteboard - Advice for teachers of mathematics. Acedido em: http://bit.ly/iwbmilleradvice, a 10/10/2012.

Miller, D., Glover, D., \& Averis, D. (2005). Presentation and pedagogy: The effective use of interactive whiteboards in mathematics lessons. In D. Hewitt \& A. Noyes (Orgs.), VI British Congress of Mathematics Education, BSRLM Proceedings (25/1, pp. 105-112). London: British Society for Research into Learning Mathematics.

Mishra, P., \& Koehler, M. (2006). Technological Pedagogical Content Knowledge: A framework for teacher knowledge. Teachers College Record, 108(6), 10171054. 
Moss, G., Jewitt, C., Levačić, R., Armstrong, V., Cadini, A., \& Castle, F. (2007). The interactive whiteboards, pedagogy and pupil performance evaluation: An evaluation of the Schools Whiteboard Expansion (SWE) project: London challenge (Research Report 816). Londres: Department for Education and Skills, University of London.

Mouraz, A., \& Sousa, J. (2011). O projecto Inovar com QI - Uma experiência de integração das TIC nos processos de ensino e aprendizagem. Educação, Formação \& Tecnologias, 4(1), 66-87.

Mueller, J., Wood, E., Willoughby, T., Ross, C., \& Specht, J. (2008). Identifying discriminating variables between teachers who fully integrate computers and teachers with limited integration. Computers and Education, 51, 1523-1537.

Niess, M. (2005). Preparing teachers to teach science and mathematics with technology: Developing a technology pedagogical content knowledge. Teaching and Teacher Education, 21, 509-523.

Niess, M. (2006). Guest editorial: Preparing teachers to teach mathematics with technology. Contemporary Issues in Technology and Teacher Education, 6(2), 195-203.

Niess, M. (2015). Transforming teachers' knowledge: Learning trajectories for advancing teacher education for teaching with technology. In C. Angeli \& N. Valanides (Eds.), Technological Pedagogical Content Knowledge: Exploring, developing, and assessing TPCK (pp. 19-37). Nova York: Springer US.

Niess, M., Ronau, R., Shafer, K., Driskell, S., Harper, S., Johnston, C., ...Kersaint, G. (2009). Mathematics teacher TPACK standards and development model. Contemporary Issues in Technology and Teacher Education, 9(1), 4-24.

Nóvoa, A. (1992). O passado e o presente dos professores. In A. Nóvoa (Org.), Profissão professor. Porto: Porto Editora.

Palis, G. (2010). O conhecimento tecnológico, pedagógico e do conteúdo do professor de Matemática. Educação Matemática Pesquisa, 12(3), 432-451.

Puentedura, R. (2013). SAMR, STEM and assessment. Disponível em: http://www.hippasus.com/rrpweblog/archives/2013/10/28/SAMR_STEM_ Assessment.pdf

Rogers, E. (2003). Diffusion of innovations ( $5^{a}$ ed.). New York: Free Press.

Sampaio, P. (2008). Uma experiência com o Excel sobre proporcionalidade directa, utilizando o quadro interactivo. In A. Silva et al. (Orgs.), ProfMat 2008 (pp. 1-10). Elvas: APM.

Sampaio, P., \& Coutinho, C. (2008). Aplicação do quadro interactivo na aprendizagem de equações. In SEM, SPCE (Org.), XVII Encontro de Investigação em Educação Matemática - XVII EIEM (pp. 344-356). Vieira de Leiria: SEM, SPCE.

Sampaio, P., \& Coutinho, C. (2011). Formação contínua de professores: Integração das TIC. FAED - Revista da Faculdade de Educação, 9(15), 139-151.

Sampaio, P., \& Coutinho, C. (2013). Quadros interativos na educação: Uma avaliação a partir das pesquisas da área. Educação e Pesquisa, 39(3), 741-756.

Sandholtz, J., Ringstaff, C., \& Dwyer, D. (1997). Teaching with technology: Technology - Creating student-centered classrooms. New York: Teacher's College Press. 
Schön, D. (1992). Formar professores como profissionais reflexivos. In A. Nóvoa (Org.), Os professores e sua formação. Lisboa: Dom Quixote.

Tardif, M. (2002). Saberes docentes e formação profissional. Petrópolis: Vozes.

United Nations Educational, Scientific and Cultural Organization - UNESCO (2009). Padrões de competência em TIC para professores - Módulos de padrão de competência. Paris: UNESCO.

Vicente, C., \& Melão, N. (2009). A adopção do quadro interactivo pelos professores de matemática do $3^{\circ} \mathrm{CEB}$ : Um estudo empírico nas escolas da Guarda. Educação, Formação \& Tecnologias, 2(2), 41-57.

Walker, D. (2002). Meet Whiteboard Wendy. Times Educational Supplement (setembro, 13). Disponível em https://www.tes.com/news/tes-archive/tes-publication/ meetwhiteboard-wendy

\section{Legislação consultada}

Ministério da Educação (2007). Resolução do Conselho de Ministros n. ${ }^{\circ}$ 137/2007 (1. ${ }^{\text {a }}$ série), de 18 de setembro de 2007.

Ministério da Educação (2009). Portaria n. ${ }^{\circ} 731 / 2009$ ( $1^{\text {a }}$ série), de 7 de julho de 2009. 


\title{
PROFESSIONAL DEVELOPMENT OF MATHEMATICS TEACHERS: AN ICT TRAINING EXPERIENCE
}

\begin{abstract}
The process of integration of ICT should come as something natural when teachers prepare their lessons. In the case of Mathematics, this inclusion is implicit in the official national syllabuses but not all teachers feel prepared to do it. This text addresses an experience involving the use of interactive whiteboards by twenty teachers according with the TPACK guidelines. This means that not only technological skills were considered but also other factors such as pedagogical and curriculum skills, as well as the context within which these were used and the relations that were created. We aimed at investigating in what way this experience would have a positive impact in their daily practices. With that aim, teachers answered online questionnaires, at the end of the training sessions, then after nine months and, finally, three years later. The results show that these teachers have changed their daily routines and the way they delivered their lessons, making it possible for them to get closer to the modern idea of a teacher of the twenty first century.
\end{abstract}

Keywords

Professional development; Mathematics TPACK; Educational technology; Interactive whiteboards

\section{EL DESARROLLO PROFESIONAL DE PROFESORES DE MATEMÁtICAS: UNA EXPERIENCIA DE FORMACIÓN EN TIC}

\section{Resumen}

La integración de las TIC es una práctica que debe ser tan natural al docente como la preparación de clases. En el caso de Matemática, esta inclusión surge implícita en los programas oficiales; sin embargo, ni todos los docentes se sienten capaces de las utilizar. Se presenta una experiencia de formación 
sobre la utilización de pizarras interactivas con 20 profesores de Matemática, según el referencial TPACK, que considera competencias tecnológicas, pedagógicas, de contenido, contextuales y todas las relaciones que se establecen. La intención era investigar si, y cómo, la formación construida en esta esfera tendría un impacto positivo en la práctica docente y se llevó a cabo un cuestionario, en el final de la formación, después de nueve meses y pasados tres años. Se constató un cambio efectivo en sus prácticas, más cerca de un maestro del siglo XXI, lo que ha promovido el suyo desarrollo profesional.

Palabras-clave

Desarrollo profesional; TPACK de las Matemáticas; Tecnología educativa; Pizarras interactivas

Recebido em maio/2015 Aceite para publicação em julho/2016

i Bolseira da Fundação para a Ciência e Tecnologia, Centro de Investigação em Estudos da Criança, Universidade do Minho, Portugal

Toda a correspondência relativa a este artigo deve ser enviada para: Patrícia Alexandra da Silva Ribeiro Sampaio, Av. Conde Margaride, 690, 4835-073 Guimarães, Portugal. E-mail: patisampaio@gmail.com 